\title{
A Ferromagnetically Coupled Octanuclear Manganese(III) Cluster: A Single-Molecule Magnet with a Spin Ground State of $S=16$
}

\author{
Takuya Shiga, ${ }^{* \dagger}$ Hiroyuki Nojiri, ${ }^{\ddagger}$ and Hiroki Oshio ${ }^{\dagger, \perp}$ \\ † Graduate School of Pure and Applied Sciences, University of Tsukuba, Tennodai 1-1-1, Tsukuba, Ibaraki 305-8571, \\ Japan \\ ‡ Institute of Materials Research, Tohoku University, Katahira 2-1-1, Sendai, Miyagi 980-8577, Japan \\ $\perp$ State Key Laboratory of Fine Chemicals, Dalian University of Technology, 2 Linggong Rd., 116024 Dalian, P. R. of \\ China
}

Polynuclear complex, Single-molecule magnet, Magnetism, Manganese, Ferromagnetic interactions.

Supporting Information Placeholder

ABSTRACT: An octanuclear manganese complex, $\left[\mathrm{Mn}^{\mathrm{III}}{ }_{8}\left(\mu_{4^{-}}\right.\right.$ $\left.\mathrm{O})_{4}(\mathrm{~L})_{4}(\mathrm{OMe})_{4}(\mathrm{OAc})_{4}\left(\mathrm{OCH}_{2} \mathrm{CH}_{2} \mathrm{NH}_{3}\right)_{4}\right] \quad$ (1) $\quad\left[\mathrm{H}_{2} \mathrm{~L}=3^{-}\right.$ (dimethoxymethyl)-2-hydroxybenzoic acid], was synthesized with an extended cubane core structure consisting of eight manganese ions bridged by oxo atoms. Cryomagnetic studies revealed that 1 showed a single-molecule magnetic behavior with an $S=16$ spin ground state.

Transition-metal clusters have been extensively investigated for their potential magnetic properties. ${ }^{1}$ Many single-molecule magnets (SMMs) have been reported, and their unique magnetic properties have been explored. ${ }^{2}$ Two basic requirements for constructing an SMM are a large ground spin state $S$ and a large negative magnetic anisotropy $D$. However, it is difficult to control both the magnetic exchange and the magnetic anisotropy of cluster molecules. Consequently, appropriate synthetic strategies for SMMs are still important, and sophisticated spin systems are higly required. The family of $\left[\mathrm{Mn}_{12} \mathrm{O}_{12}\left(\mathrm{O}_{2} \mathrm{CR}\right)_{16}\left(\mathrm{H}_{2} \mathrm{O}\right)_{4}\right]$ is one of the most intensively studied group of SMMs. 3 The manganese ion is a useful metal ion for constructing molecular magnetic materials because of its variety of oxidation/spin states [Mn(II), Mn(III), and $\mathrm{Mn}(\mathrm{IV})]$ and the significant magnetic anisotropy of the $\mathrm{Mn}(\mathrm{III})$ ion. Therefore, several SMMs composed of manganese ions have been reported, and it is known that the complexity of their structures has tended to increase with increasing molecular size. $4 \mathrm{~A}$ number of spin clusters have been developed by using various ligands. For examples, the $\mathrm{Mn}_{84}$ complex, $\left[\mathrm{Mn}_{84} \mathrm{O}_{72}(\mathrm{OH})_{6}\left(\mathrm{CH}_{3} \mathrm{CO}_{2}\right)_{78}(\mathrm{OMe})_{24}(\mathrm{MeOH})_{12}\left(\mathrm{H}_{2} \mathrm{O}\right)_{42}\right]$, has a giant wheel structure with a spin ground state of $S=6.5$ The $\mathrm{Mn}_{19}$ complex, $\left[\mathrm{Mn}_{7}^{\mathrm{II}} \mathrm{Mn}^{\mathrm{III}}{ }_{12} \mathrm{O}_{8}\left(\mathrm{~N}_{3}\right)_{8}(\mathrm{Hbhmmp})_{12}(\mathrm{MeCN})_{6}\right] \mathrm{Cl}_{2}$ [ $\mathrm{H}_{2}$ bhmmp $=$ 2,6-bis(hydroxymethyl)-4-methylphenol], has an $S=83 / 2$ spin ground state and a low blocking temperature
$\left(T_{\mathrm{B}}\right)$ of $0.5 \mathrm{~K}$, which is due to its small magnetic anisotropy. ${ }^{6} \mathrm{It}$ was previously suggested that a balance between a high spin ground state and a large negative magnetic anisotropy is difficult to achieve by means of serendipitous synthetic methods. ${ }^{2}$ To prepare SMMs with a high blocking temperature, it is important to explore new cluster cores constructed with proper ligands.

In constructions of polynuclear complexes with high ground spin states, it is known that cubanes and stacked triangles are excellent magnetic cores. A tetranuclear cubane core consisting of four metal ions bridged by oxygen atoms is a well-known structural motif. Such cubane cores tend to display ferromagnetic interactions, which is due to the accidental orthogonality of the magnetic orbitals. ${ }^{7}$ We have previously reported several examples of alkoxo-bridged tetranuclear ferrous cubes, derived from Schiff-base ligands, that display superparamagnetic behavior. ${ }^{8}$ On the other hand, stacked triangle cores consisting of six metal ions bridged by $\mu_{3}-\mathrm{O}$ and oxime groups have also been well investigated. Brechin and co-workers reported a series of $\mathrm{Mn}_{6} \mathrm{SMMs}$ with the stacked triangle core.9 In such systems, intramolecular magnetic exchange interactions are sensitive to the $\mathrm{Mn}-\mathrm{N}-\mathrm{O}-$ Mn torsion angles of the oxime bridges, resulting in various spin ground state from $S=4$ to $S=12$. However, these complexes have a large and negative magnetic anisotropy associated with the presence of Jahn-Teller-distorted Mn(III) ions aligned in the direction perpendicular to the plane of the $\left\{\mathrm{Mn}_{3} \mathrm{O}\right\}$ triangle.

With this background in mind, we attempted to synthesize various polynuclear complexes containing regular arrays of metal ions, such as triangles, cubes, rings, wheels, grids, helices, or Keggins, by using several rigid and planar ligands. ${ }^{10}$ In our search for polynuclear manganese complexes with high ground spin states, we obtained a new manganese complex by serendipitous supramolecular assembly through hydrogen 
bonds, accompanied by acetalization of the ligand. Here, we report the synthesis, structure, and magnetic properties of an octanuclear manganese cluster, $\left[\mathrm{Mn}^{\mathrm{III}}{ }_{8}\left(\mu_{4}-\right.\right.$ $\left.\mathrm{O})_{4}(\mathrm{~L})_{4}(\mathrm{OMe})_{4}(\mathrm{OAc})_{4}\left(\mathrm{OCH}_{2} \mathrm{CH}_{2} \mathrm{NH}_{3}\right)_{4}\right] \quad$ (1) $\quad\left[\mathrm{H}_{2} \mathrm{~L}=3^{-}\right.$ (dimethoxymethyl)-2-hydroxybenzoic acid], which has a high spin ground state of $S=16$, and showed SMM behavior.

Chart 1. Structures of the Ligands Used in This Work<smiles>O=Cc1cccc(C(=O)O)c1O</smiles><smiles>COC(OC)c1cccc(C(=O)O)c1O</smiles>

The reaction of $\mathrm{Mn}(\mathrm{OAc})_{2} \cdot 4 \mathrm{H}_{2} \mathrm{O}$ with $\mathrm{H}_{2} \mathrm{~L}^{\prime} \quad\left(\mathrm{H}_{2} \mathrm{~L}^{\prime}=3^{-}\right.$ formylsalicylic acid), 2-aminoethanol, and $\mathrm{Et}_{3} \mathrm{~N}$ in methanol gave the octanuclear manganese complex 1 after recrystallization from acetonitrile. During the synthesis of complex 1, the formyl group of $\mathrm{H}_{2} \mathrm{~L}$ ' was transformed into a dimethoxymethyl group by acetalization. ${ }^{11}$ Complex $\mathbf{1}$ crystallized in the monoclinic space group $C_{2} / c$ (Table $\mathrm{S}_{1}$ ). The asymmetric unit consists of a half of $\left[\mathrm{Mn}^{\mathrm{III}} 8\left(\mu_{4^{-}}\right.\right.$ $\left.\mathrm{O})_{4}(\mathrm{~L})_{4}(\mathrm{OMe})_{4}(\mathrm{OAc})_{4}\left(\mathrm{OCH}_{2} \mathrm{CH}_{2} \mathrm{NH}_{3}\right)_{4}\right]$, and three acetonitrile molecules. In this structure, the amino group of 2aminoethanol is protonated to form an ammonium cation, whereas the hydroxy group is deprotonated and coordinates to two manganese ions in a $\mu_{2}$-bridging mode. The structure of 1 contains a $\left[\mathrm{Mn}^{\mathrm{III}}{ }_{8}\left(\mu_{4}-\mathrm{O}\right)_{4}\left(\mu_{2}-\mathrm{O}\right)_{8}\right]$ core in which four $\mu_{4}-\mathrm{O}$ are oxide ion, four $\mu_{2}-\mathrm{O}$ atoms are derived from the 2aminoethanol moiety and four $\mu_{2}-\mathrm{O}$ atoms are derived from the methoxide anion. The core can be considered as a faceshared defective pentacubane, which appears to be an extended cubane structure. There are four crystallographically independent manganese(III) ions with Jahn-Teller distortion; these are classified into peripheral ions ( $\mathrm{Mn}_{1}$ and $\mathrm{Mn}_{3}$ ) and central ions (Mn2 and Mn4). The Mnı and Mnz ions are in an $\mathrm{O}_{6}$ coordination sphere of peripheral sites, with two oxygen atoms from the ligand, one oxygen atom from the 2aminoethanol moiety, one oxygen atom from the methoxide anion, one $\mu_{4}-\mathrm{O}$ atom, and one oxygen atom from the acetate anion. The $\mathrm{Mn}_{2}$ and $\mathrm{Mn}_{4}$ ions are in an $\mathrm{O}_{6}$ coordination sphere of the central $\mathrm{Mn}_{4} \mathrm{O}_{4}$ cubane core, with three $\mu_{4}-\mathrm{O}$ atoms, one oxygen atom from the 2-aminoethanol moiety, one oxygen atom from the methoxide anion, and one oxygen atom from the acetate anion. The manganese(III) oxidation states were established by considering bond lengths, bond valence sum calculations (Table S2), and the presence of elongated Jahn-Teller distortions, as expected for octahedral manganese(III) centers. The Jahn-Teller axes of the four manganese ions in peripheral sites are approximately parallel to each other with an elongated Mn1-O6, Mn1-O17, $\mathrm{Mn}_{3}-\mathrm{O}_{3}$, and $\mathrm{Mn}_{3}-\mathrm{O}_{19}$ bond lengths. In contrast, the Jahn-Teller axes (Mn2-O1, Mn2-O2, Mn4-O4, and $\mathrm{Mn}_{4}-\mathrm{O}_{5}$ ) of the four manganese ions in central sites lie perpendicular to the pseudo molecular $S_{4}$ axis, resulting in a uniaxial magnetic easy axis (Figure $\mathrm{S} 1$ ). In the $\mathrm{Mn}_{4} \mathrm{O}_{4}$ cubane core, the $\mathrm{Mn}-\mathrm{O}-\mathrm{Mn}$ bond angles are in the range 90.94-104.73 ${ }^{\circ}$, whereas the $\mathrm{Mn}-$ $\mathrm{O}-\mathrm{Mn}$ bond angles between the manganese ions of the central and peripheral sites are in the range $92.35^{-103.96^{\circ}}$. The neighboring $\mathrm{Mn} \cdots \mathrm{Mn}$ separations in the octanuclear core are in the range 2.963-3.194 $\AA$. The shortest intermolecular $\mathrm{Mn} \cdots \mathrm{Mn}$ separation is 8.129 $\AA$. Methyl group of $\mathrm{AcO}^{-}$ion interacts with phenyl ring of neighboring $\mathrm{Mn}_{8}$ cluster through $\mathrm{CH} \cdots \pi$ interactions (Figure $\mathrm{S}_{2}$ ).

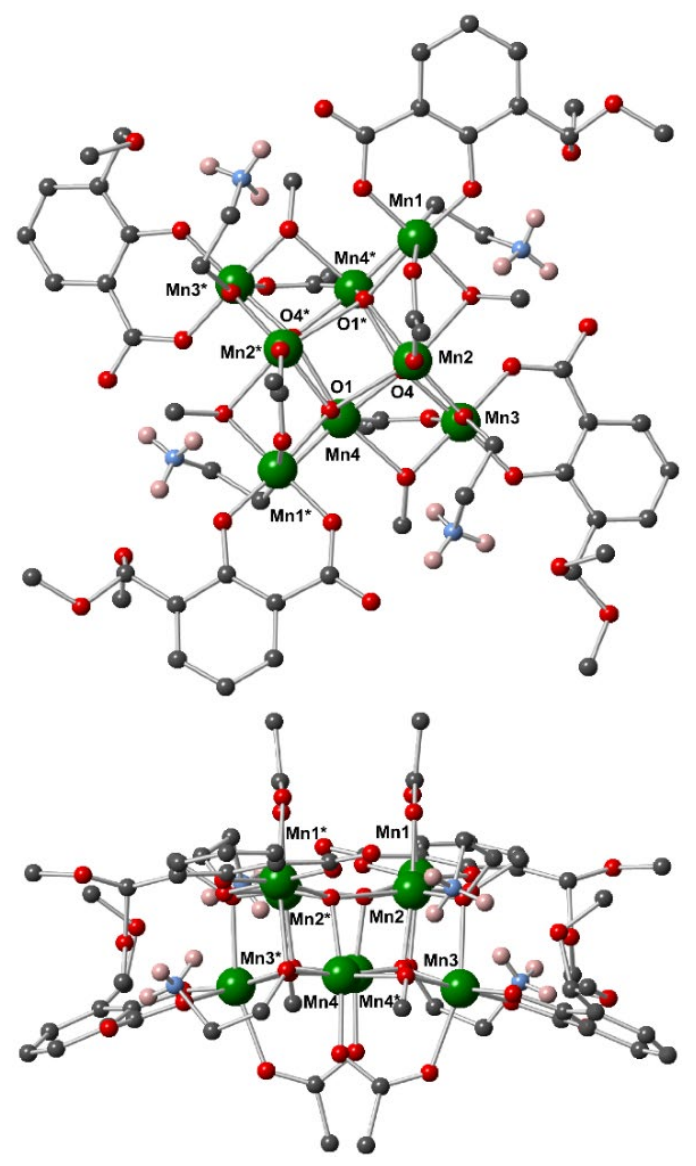

Figure 1. Molecular structure of 1. Top: top view. Bottom: side view. Only the $\mathrm{H}$ atoms that are part of the ammonium group of 2-aminoethanol are shown. Color code: $\mathrm{C}$, gray; $\mathrm{N}$, light blue; $\mathrm{Mn}^{\mathrm{III}}$, green. Symmetry code: ${ }^{*} 2-x,+y, 3 / 2-z$. Solvent molecules are excluded for clarity.

Complex 1 has a unique intramolecular hydrogen bond, $\mathrm{N}-$ $\mathrm{H} \cdots \mathrm{O}-\mathrm{C}$, between the ammonium group of the 2aminoethanol moiety and the oxygen of the ligand (Table $\mathrm{S}_{3}$ ). The formation of this intramolecular interaction contributes to the stability of the octanuclear cluster structure.

Magnetic susceptibility measurements for 1 were performed in the temperature range $1.8-300 \mathrm{~K}$ with an applied magnetic field of 500 Oe. Plots of $\chi_{\mathrm{m}} T$ versus $T$ are shown in Figure 2. At room temperature, the values of the $\chi_{\mathrm{m}} T$ product $(28.137 \mathrm{emu}$ $\mathrm{mol}^{-1} \mathrm{~K}$ ) are larger than the expected spin-only value (24 emu $\mathrm{mol}^{-1} \mathrm{~K}$ ) for eight magnetically isolated manganese(III) ions $(S=2)$. The $\chi_{\mathrm{m}} T$ values gradually increased with decreasing temperature to a maximum value of 136.0 emu $\mathrm{mol}^{-1} \mathrm{~K}$ at 5.5 $\mathrm{K}$. The value of $\chi_{\mathrm{m}} T$ decreased to $112.9 \mathrm{emu} \mathrm{mol}^{-1} \mathrm{~K}$ at $1.8 \mathrm{~K}$ due to zero-field splitting. This magnetic behavior is indicative of the presence of intramolecular ferromagnetic interactions between manganese(III) ions. The magnetic behavior above 5 $\mathrm{K}$ was fitted by MAGPACK, based on an eight-center spin 
model with two kinds of magnetic exchange interactions $J_{1}$ and $\mathrm{J}_{2}$ without magnetic anisotropy terms (Figure 2, inset) with the following spin Hamiltonian:12

$$
\begin{aligned}
H= & -2 J_{1}\left(S_{2} \cdot S_{4}+S_{2} \cdot S_{6}+S_{2} \cdot S_{8}+S_{4} \cdot S_{6}+S_{4} \cdot S_{8}+S_{6} \cdot S_{8}\right)- \\
& 2 J_{2}\left(S_{1} \cdot S_{2}+S_{1} \cdot S_{8}+S_{2} \cdot S_{3}+S_{3} \cdot S_{4}+S_{4} \cdot S_{5}+S_{5} \cdot S_{6}+\right. \\
& \left.S_{6} \cdot S_{7}+S_{7} \cdot S_{8}\right) .
\end{aligned}
$$

Ferromagnetic interactions were estimated with $J_{1}=+5.0 \mathrm{~K}$ and $J_{2}=+2.3 \mathrm{~K}$ with $g=1.98$. The discrepancy factor $R\left(\chi_{\mathrm{m}}\right)$ was $3.56 \times 10^{-2}$ and $R\left(\chi_{\mathrm{m}} T\right)$ was $2.98 \times 10^{-2} .1$ has a perpendicular alignment of Jahn-Teller axis through $\mu$-O bridges, thus the ferromagnetic interactions are expected. ${ }^{3}$ Magnetization experiments for $\mathbf{1}$ were carried out and the reduced magnetization versus $H / \mathrm{T}$ plots are shown in Figure 2 (right). The magnetization of $\mathbf{1}$ saturated with a value of $29.8 \mathrm{~N} \beta$ when the magnetic field exceeded $5.0 \mathrm{~T}$ at $1.8 \mathrm{~K}$. The reduced magnetization data in the $1.8-3.0 \mathrm{~K}$ and $2-5 \mathrm{~T}$ ranges were fitted by assuming an $S=16$ spin ground state with $g=1.98$, $D / \mathrm{k}_{\mathrm{B}}=-0.15 \mathrm{~K}, E / \mathrm{k}_{\mathrm{B}}=0.05 \mathrm{~K}$, and $B_{4}{ }^{\mathrm{o}}=3.0 \times 10^{-5} \mathrm{~K}$.
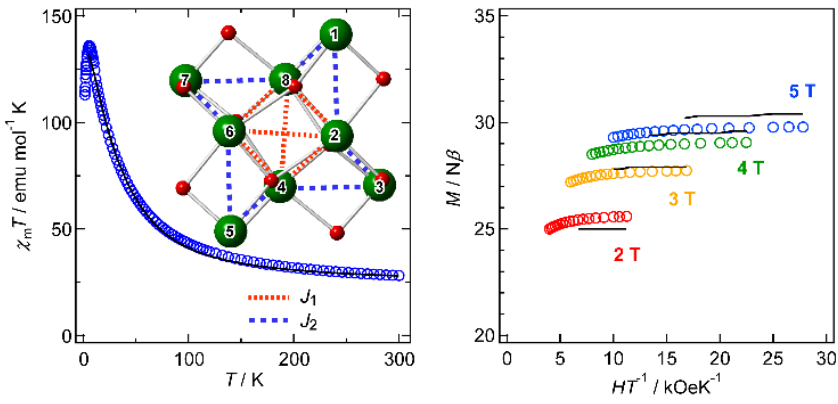

Figure 2. Left: Plots of $\chi_{\mathrm{m}} T$ versus $T$ for 1 . The solid line represents the fit of the data to the theoretical model. The schematic in the inset is a spin model for fitting of the magnetic data. Right: The reduced magnetization $M / N \beta$ versus $H / \mathrm{T}$ plots for $\mathbf{1}$ at $2-5 \mathrm{~T}$. The solid lines correspond to the fit of the data (see text for details).
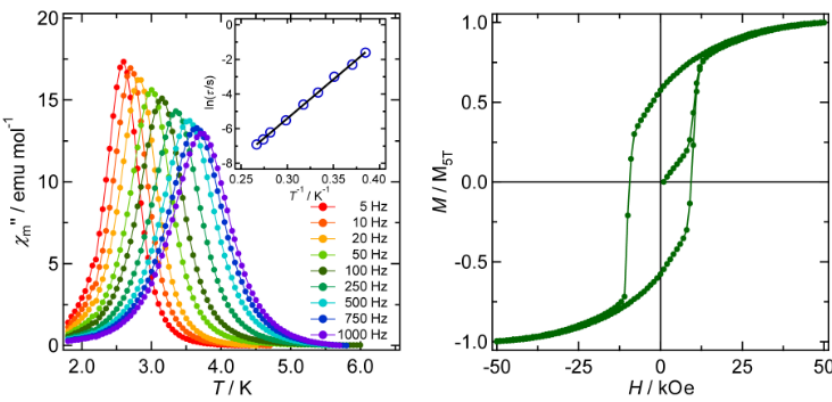

Figure 3. Left: Frequency dependences of the out-of-plane magnetic susceptibility $\left(\chi_{\mathrm{m}}\right)$ ) for $\mathbf{1}$ at various temperatures between 1.8 and 6.o $\mathrm{K}$ under zero external magnetic dc field. An Arrhenius plot from the position of the $\chi_{\mathrm{m}}$ " peaks is shown in the inset. Right: Magnetization versus magnetic field for aligned single crystals of 1 at $450 \mathrm{mK}(H \perp a$ axis).

We carried out ac magnetic susceptibility studies under zero external dc field (Figure 3 , left; Figure $\mathrm{S}_{1}$ ). The $\chi_{\mathrm{m}}$ " versus $T$ plots for various frequencies led to well-defined maxima in the temperature range 1.8-6.o K. Analysis of the linear variation of 1 with the Arrhenius law $\tau=\tau_{\mathrm{o}} \exp \left(U_{\text {eff }} / k_{\mathrm{B}} T\right)$ gave $U_{\text {eff }} / k_{\mathrm{B}}=45.14 \mathrm{~K}$ with $\tau_{\mathrm{o}}=5.85 \times 10^{-9} \mathrm{~s}$. Magnetizations in the direction perpendicular to the magnetization hard axis were measured for aligned single crystals of $\mathbf{1}$ in a static magnetic field at $450 \mathrm{mK}$ (Figure 3, right). The $M / M_{5} \mathrm{~T}$ versus $H$ plots showed a distinct hysteresis loops with a step at $9 \mathrm{kOe}$.

The high-field EPR spectra obtained with a pulsed magnetic field are shown in Figure 4 (left) and Figure S2. The temperature dependences of the EPR spectra for the powder sample were collected at $190 \mathrm{GHz}$ (Figure 4, left). The spectrum at 4.2 K showed the most intense band at 3.9 T, and more fine structure was observed for the EPR signals at higher temperatures in the higher-magnetic-field region. This is due to the appreciable thermal energy needed to populate higherenergy $M_{\mathrm{S}}$ levels; moreover, the temperature dependence of the EPR signals indicates that $\mathbf{1}$ has a negative $D$ value. Zeeman splitting of the $S=16$ state, calculated with $D=-0.15 \mathrm{~K}, E=$ $0.05 \mathrm{~K}, B_{4}{ }^{\circ}=3.0 \times 10^{-5} \mathrm{~K}$, and $g=1.98$ by using the Hamiltonian below:

$$
\boldsymbol{H}=g \mu_{\mathrm{B}} H+D\left[\boldsymbol{S}_{\mathrm{z}-1} / 3 S(S+1)\right]+E\left(\boldsymbol{S}_{x}-\boldsymbol{S}_{y}\right)+B^{\circ}{ }_{4} \mathrm{O}^{\circ}{ }_{4}
$$

The expected resonance lines were plotted with the observed peaks (Figure 4, right). These parameters are consistent with the above-mentioned magnetic-fitting parameters.
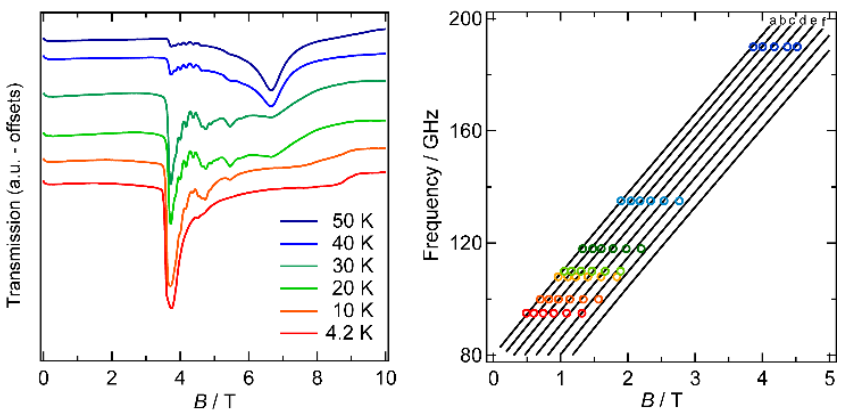

Figure 4. Left: Temperature dependences of high-field EPR spectra of a powder sample of 1 measured at $190 \mathrm{GHz}$. Right: Plots of the frequency versus the resonance magnetic field $B$ for the observed peaks. Solid lines on the frequency versus magnetic field plots were calculated from $S=16, D=-0.15 \mathrm{~K}$, $E=0.05 \mathrm{~K}$, and $B_{4}{ }^{0}=3.0 \times 10^{-5} \mathrm{~K}$ (see text for details). Assignments: $a, m=-16 \rightarrow-15$; b, $m=-15 \rightarrow-14$; c, $m=-14$ $\rightarrow-13 ; \mathrm{d}, m=-13 \rightarrow-12$; e, $m=-12 \rightarrow-11 ; \mathrm{f}, m=-11 \rightarrow-10$.

In summary, an octanuclear manganese complex with an extended cubane core structure consisting of eight manganese ions bridged by oxo atoms was synthesized. Cryomagnetic studies revealed that $\mathbf{1}$ displays a single-molecule magnetic behavior with an $S=16$ spin ground state and a negative magnetic anisotropy of $D=-0.15 \mathrm{~K}$, as confirmed by the magnetization hysteresis and high-field EPR measurements. The obtained octanuclear Mn(III) complex has a maximum spin ground state of $S=16$, which is the first case among known octanuclear Mn(III) complexes (Table $\mathrm{S}_{4}$ ). The present study shows that the extended cubane core structure is a good motif for constructing high-performance SMMs due to the presence of effective ferromagnetic interactions.

\section{ASSOCIATED CONTENT}

\section{Supporting Information}


The Supporting Information is available free of charge on the ACS Publications website at DOI: 10.1021/acs.inorgchem.XXXXXXX.

Experimental and characterization details, detail synthetic procedure, crystal data, a real part of ac magnetic susceptibility data and EPR spectra of $\mathbf{1}$.

\section{Accession Codes}

CCDC 1959643 contains the supplementary crystallographic data for $\mathbf{1}$ at $200 \mathrm{~K}$. These data can be obtained free of charge via www.ccdc.cam.ac.uk/data_request/cif, or by emailing data_request@ccdc.cam.ac.uk, or by contacting The Cambridge Crystallographic Data Centre, 12 Union Road, Cambridge CB2 1EZ, UK; fax: +44 1223336033.

\section{AUTHOR INFORMATION}

\section{Corresponding Author}

*E-mail: shiga@chem.tsukuba.ac.jp

\section{ORCID}

Takuya Shiga: oooo-ooo2-6834-6o11

Hiroki Oshio: oooo-00o2-4682-4705

\section{Author Contributions}

The manuscript was written with contributions by all authors. Notes

The authors declare no competing financial interests.

\section{ACKNOWLEDGMENT}

We gratefully acknowledge a Grant-in-Aid for Scientific Research (C) (No. 17Ko580o), a Grant-in-Aid for Challenging Exploratory Research (No. 18K19088), and Grant-in-Aid for Scientific Research on Innovative Areas 'Coordination Asymmetry' (No. JP16Ho6523) from the Japan Society for the Promotion of Science (JSPS).

\section{REFERENCES}

(1) (a) Papatriantafyllopoulou, C.; Moushi, E. E.; Christou, G.; Tasiopoulos, A. J. Filling the Gap between the Quantum and Classical Worlds of Nanoscale Magnetism: Giant Molecular Aggregates Based on Paramagnetic 3d Metal Ions. Chem. Soc. Rev. 2o16, 45, 1597-1628. (b) Escur, A.; Esteban, J.; Perlepes, S. P.; Stamatatos, T. C. The Bridging Azido Ligand as a Central "Player" in High-Nuclearity 3d-Metal Cluster Chemistry. Coord. Chem. Rev. 2014, 275, 87-129.

(2) (a) Gatteschi, D.; Sessoli, R.; Villain, J. Molecular Nanomagnets; Oxford University Press: Oxford, 2006. (b) Aromi, G.; Brechin, E. K. In Single-Molecule Magnets and Related Phenomena; Winpenny, R., Ed.; Springer: Berlin, 2006. (c) Gao, S. Molecular Nanomagnets and Related Phenomena; Springer: Berlin, 2015. (d) Maniaki, D.; Pilichos, E.; Perlepes, S. P. Coordination Clusters of 3d-Metals That Behave as Single-Molecule Magnets (SMMs): Synthetic Routes and Strategies. Front. Chem. (Lausanne, Switz.) 2018, 6, 461.

(3) (a) Bagai, R.; Christou, G. The Drosophila of Single-Molecule Magnetism: $\left[\mathrm{Mn}_{12} \mathrm{O}_{12}\left(\mathrm{O}_{2} \mathrm{CR}\right)_{16}\left(\mathrm{H}_{2} \mathrm{O}\right)_{4}\right]$. Chem. Soc. Rev. 2009, 38, 10111026. (b) Sessoli, R.; Gatteschi, D.; Caneschi, A.; Novak, M. A. Magnetic Bistability in a Metal-Ion Cluster. Nature, 1993, 365, 141-143; (c) Sessoli, R.; Tsai, H. L.; Schake, A. R.; Wang, S.; Vincent, J. B.; Folting, K.; Gatteschi, D.; Christou, G.; Hendrickson, D. N. High-Spin Molecules: $\left[\mathrm{Mn}_{12} \mathrm{O}_{12}\left(\mathrm{O}_{2} \mathrm{CR}\right)_{16}\left(\mathrm{H}_{2} \mathrm{O}\right)_{4}\right]$. J. Am. Chem. Soc. 1993, 115, 1804-1816.

(4) Kostakis, G. E.; Ako, A. M.; Powell, A. K. Structural Motifs and Topological Representation of Mn Coordination Clusters. Chem. Soc. Rev. 2010, 39, 2238-2271.
(5) Tasiopoulos, A. J.; Vinslava, A.; Wernsdorfer, W.; Abboud, K. A. Christou, G. Giant Single-Molecule Magnets: A [Mn ${ }_{84}$ ] Torus and Its Supramolecular Nanotubes. Angew. Chem. Int. Ed., 2004, 43, 2117-2121. (6) Ako, A. M.; Hewitt, I. J.; Mereacre, V.; Clérac, R.; Wernsdorfer, W.; Anson, C. E.; Powell, A. K. A Ferromagnetically Coupled $\mathrm{Mn}_{19}$ Aggregate with a Record $S=83 / 2$ Ground Spin State. Angew. Chem. Int. Ed. 2006, 45, 4926-4929.

(7) Nakano, M.; Oshio, H. High-Spin Molecules with Magnetic Anisotropy Towards SMM. Chem.-Eur. J. 2005, 11, 5178-5185.

(8) (a) Oshio, H.; Hoshino, N.; Ito, T.; Nakano, M. Single-Molecule Magnets of Ferrous Cubes: Structurally Controlled Magnetic Anisotropy. J. Am. Chem. Soc. 2004, 126, 8805-8812. (b) Oshio, H.; Hoshino, N.; Ito, T. Superparamagnetic Behavior in an AlkoxoBridged Iron(II) Cube. J. Am. Chem. Soc. 20oo, 122, 12602-12603.

(9) (a) Milios, C. J.; Vinslava, A.; Wood, P. A.; Parsons, S.; Wernsdorfer, W.; Christou, G.; Perlepes, S. P.; Brechin, E. K. A Single-Molecule Magnet with a "Twist", J. Am. Chem. Soc. 2007, 129, 8-9.; (b) Milios, C. J.; Vinslava, A.; Wernsdorfer, W.; Moggach, S.; Parsons, S.; Perlepes, S. P.; Christou, G.; Brechin, E. K. A Record Anisotropy Barrier for a Single-Molecule Magnet. J. Am. Chem. Soc. 2007, 129, 2754-2755.; (c) Milios, C. J.; Vinslava, A.; Wernsdorfer, W.; Prescimone, A.; Wood, P. A.; Parsons, S.; Perlepes, S. P.; Christou, G.; Brechin, E. K. Spin Switching via Targeted Structural Distortion. J. Am. Chem. Soc. 2007, 129, 6547-6561; (d) Milios, C. J.; Inglis, R.; Vinslava, A.; Bagai, R.; Wernsdorfer, W.; Parsons, S.; Perlepes, S. P.; Christou, G.; Brechin, E. K. Toward a Magnetostructural Correlation for a Family of $\mathrm{Mn}_{6} \mathrm{SMMs}$, J. Am. Chem. Soc., 2007, 129, 12505-12511.

(10) (a) Shiga, T.; Newton, G. N.; Oshio, H. Pre-programmed SelfAssembly of Polynuclear Clusters. Dalton Trans. 2018, 47, 7384-7394. (b) Newton, G. N.; Yamashita, S.; Hasumi, K.; Matsuno, J.; Yoshida, N.; Nihei, M.; Shiga, T.; Nakano, M.; Nojiri, H.; Wernsdorfer, W.; Oshio, H. Redox Controlled Magnetic $\left\{\mathrm{Mn}_{13}\right\}$ Keggins. Angew. Chem. Int. Ed. 2011, 50, 5716-5720. (c) Newton, G. N.; Hoshino, N.; Matsumoto, T.; Shiga, T.; Nakano, M.; Nojiri, H.; Wernsdorfer, W.; Furukawa, Y.; Oshio, H. Studies on the Magnetic Ground State of a Spin Möbius Strip. Chem.-Eur. J. 2016, 22, 14205-14212. (d) Matsumoto, T.; Sato, Y.; Shiga, T.; Oshio, H. Planar Copper and Nickel Triangles with a Guanidine-Derived Ligand. Inorg. Chem. Front. 2015, 2, 725-730. (e) Hoshino, N.; Ako, A. M.; Powell, A. K.; Oshio, H. Molecular Magnets Containing Wheel Motifs. Inorg. Chem. 2oo9, 48, 3396-3407. (f) Hoshino, N.; Nakano, M.; Nojiri, H.; Wernsdorfer, W.; Oshio, H. Templating Odd Numbered Magnetic Rings: Oxovanadium Heptagons Sandwiched by $\beta$-Cyclodextrins. J. Am. Chem. Soc. 2009, 131, 15100-15101. (g) Koizumi, S.; Nihei, M.; Shiga, T.; Nakano, M.; Nojiri, H.; Bircher, R.; Waldmann, O.; Güdel, H. U.; Oshio, H. A WheelShaped Single Molecule Magnet of [ $\left.\mathrm{Mn}_{3}{ }_{3} \mathrm{Mn}^{\mathrm{III}}{ }_{4}\right]$ : Quantum Tunneling of Magnetization under Static and Pulse Magnetic Field. Chem.-Eur. J. 2007, 13, 8445-8453. (h) Koizumi, S.; Nihei, M.; Nakano, M.; Oshio, H. Antiferromagnetic Fe ${ }^{\mathrm{III}}$ Ring and Single-Molecule Magnet $\mathrm{Mn}^{\mathrm{III}}$ Wheel. Inorg. Chem. 2005, 44, 1208-1210.

(11) (a) Clerici, A.; Pastri, N.; Porta, O. Efficient Acetalisation of Aldehydes Catalyzed by Titanium Tetrachloride in a Basic Medium. Tetrahedron, 1998, 54, 15679-1569o. (b) Gorla, F.; Venanzi, L.M. 7o. Cationic Palladium(II), Platinum(II), and Rhodium(I) Complexes as Acetalisation Catalysts. Helv. Chim. Acta 1990, 73, 690-697. (c) Ott, J.; Tombo, G.M.; Shmid, B.; Venanzi, L.M., Wong, G.; Ward, T.R. A Versatile Rhodium Catalyst for Acetalization Reactions under Mild Conditions. Tetra. Lett. 1989, 45, 6151-6154. (d) Gemal, A.L.; Luche, J.L. Lanthanoids in Organic Synthesis. 4.1 Selective Ketalization and Reduction of Carbonyl Groups. J. Org. Chem. 1979, 44, 4187-4189. (12) Borrás-Almenar, J. J.; Clemente-Juan, J. M.; Coronado, E.; Tsukerblat, B. S. MAGPACK': A Package to Calculate the Energy Levels, Bulk Magnetic Properties, and Inelastic Neutron Scattering Spectra of High Nuclearity Spin Clusters. J. Comput. Chem. 2oo1, 22, 985-991. (13) Berg, N.; Rajeshkumar, T.; Taylor, S.M.; Brechin, E.K.; Rajaraman, G.; Jones, L.F. What Controls the Magnetic Interaction in bis-mAlkoxo MnIII Dimers? A Combined Experimental and Theoretical Exploration. Chem. Eur. J. 2012, 18, 5906-5918. 


\section{Table of Contents}

The octanuclear manganese complex $\left[\mathrm{Mn}^{\mathrm{III}} 8\left(\mu_{4}-\mathrm{O}\right)_{4}(\mathrm{~L})_{4}(\mathrm{OMe})_{4}(\mathrm{OAc})_{4}\left(\mathrm{OCH}_{2} \mathrm{CH}_{2} \mathrm{NH}_{3}\right)_{4}\right] \quad(\mathbf{1}) \quad\left[\mathrm{H}_{2} \mathrm{~L} \quad=\quad 3^{-}\right.$ (dimethoxymethyl)-2-hydroxybenzoic acid] was synthesized with an extended cubane core structure consisting of eight manganese ions bridged by oxo atoms. Cryomagnetic studies revealed that $\mathbf{1}$ displays single-molecule magnetic behavior with an $S=16$ spin ground state.

An Ogtanuslear Mlanganese(III) SingloMMolecule Magnet

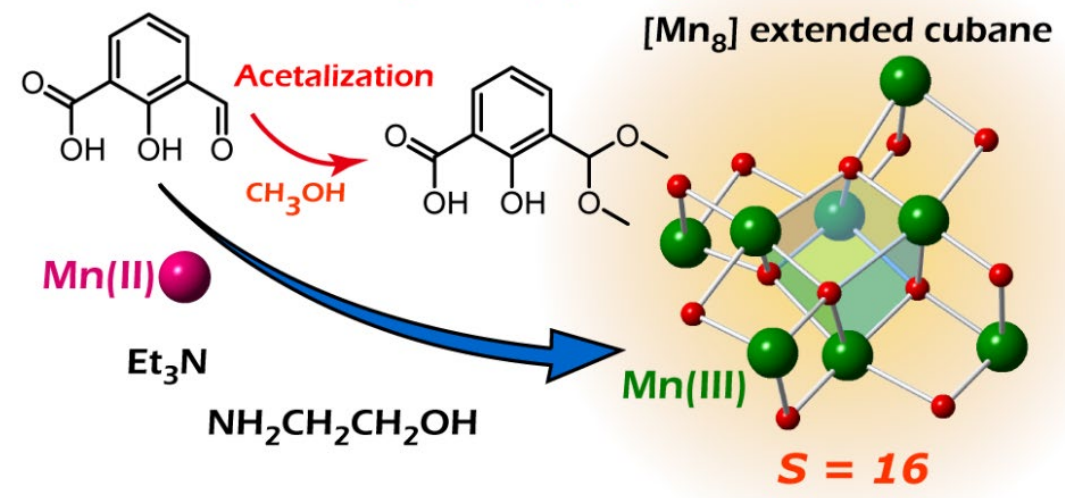

